Article

\title{
Towards Rational Design of Nanoparticle Catalysis in Ionic Liquids
}

\section{Bin Zhang and Ning Yan*}

Department of Chemical and Biomolecular Engineering, National University of Singapore, 4 Engineering Drive 4, 117576, Singapore; E-Mail: a0107193@nus.edu.sg

* Author to whom correspondence should be addressed; E-Mail: ning.yan@nus.edu.sg; Tel: +65-6516-2886; Fax: +65-6779-1936.

Received: 17 April 2013; in revised form: 14 May 2013 / Accepted: 23 May 2013 /

Published: 5 June 2013

\begin{abstract}
This feature article introduces the strategies on the design of highly efficient nanoparticle (NP) catalytic systems in ionic liquids (ILs). The employment of functional ILs as the media for NP preparation and catalysis could prove advantageous in terms of enhancing both NP stability and catalytic activity. Hydroxyl group functionalized ILs, in particular, exhibited a remarkable promotion effect on a variety of reactions catalyzed by NPs, such as hydrogenation over Rh NPs, hydrodehalogenation over Pt NPs and Suzuki reaction over Pd NPs. In some cases, tailor-made stabilizer is used in addition to keep the NPs sufficiently stable. For example, a carboxylic group modified polyvinylpyrrolidone endows NPs three-fold stabilization, including steric, electrostatic and ligand stabilizations, which leads to excellent stability of the NPs. The catalytic activities of these NPs, on the other hand, are not compromised, as each of these stabilizations is not too strong. Following that, the article describes our recent work on the rational design of bimetallic NPs in ILs and the development of multifunctional systems involving NPs for a tandem reaction sequence that convert lignin-derived phenolic compounds into fuels.
\end{abstract}

Keywords: ionic liquid; NP catalysis; stabilizer; green catalysis 


\section{Introduction}

Since the first report concerning the synthesis and immobilization of metal nanoparticles (NPs) in ionic liquid (IL) in 2002 [1], the research interest on the synthesis and application of NPs in ILs has experienced an exponential growth, with a number of publications well above one thousand to date. The main advantage of using ILs is their dual role as both reaction solvent and NP stabilizer. Stable suspensions of metal NPs can be synthesized in ILs, because the cationic and anionic species act as electrostatic stabilizers. However, NP immobilization and stabilization is not the only benefit of ILs in catalysis, of greater importance are the positive effects of ILs on catalytic rates and selectivity [2]. Indeed, some reactions catalyzed by NPs exhibit unusual, but desired selectivity patterns when performed in ILs, due to the unique microenvironment created by the anions/cations. ILs, by virtue of having a synthetically accessible carbon backbone, are amenable to tailoring by chemists to provide tunable properties, which can then be used to rationally control the catalytic performance of NPs by modifying their surface. In addition, the tunable miscibility of ILs enables facial recycling of the solvents, as well as the immobilized NPs. Finally, the reactant can reach the catalytic sites (NP surface) through solvent diffusion, thus behaving similar to homogenous systems, and is superior to support porous catalysts in this respect $[3,4]$. These advantages, coupled with the intrinsic green nature of ILs, made NPs in ILs an appealing field to explore.

Currently, metal NPs immobilized in ILs have been successfully employed in a wide range of catalytic reactions, including hydrogenation [5-9], oxidation [10,11], coupling [12-16] and others [17-21]. Nevertheless, these NP catalysts encounter many challenges. These include: poor dispersion of some NPs in ILs; low catalytic activity and/or selectivity for certain reactions; precipitation/agglomeration of NPs upon recycling (which is often accompanied with decreased catalytic activity). Tremendous efforts have been paid to address these problems, and many strategies prove to be effective. These advances and achievements are comprehensively described in some excellent reviews [22-28].

The main goal of this feature article is to present the main work that we have done in this domain in the past few years. Representative examples will be discussed to outline four different strategies that were used to improve the synthesis and catalytic applications of NPs in ILs. The article starts by discussing the cation and anion effects on the NP formation and catalytic property. Emphasis is put on hydroxyl group functionalized ILs to illustrate the cation effect. The anion effect is introduced based on experimental observation and theoretical calculation of the properties of Pd NPs in ILs with the same cation, but a variety of anions (Section 2). Section 3 discusses the strategies of designing additional stabilizers to promote the stability of NPs without (significantly) hindering their activity. The article describes both the stabilizers based on the modification of polyvinylpyrrolidone (PVP) and on the modification of bipyridine (bipy). Following that, the article describes the synthesis, characterization and application of bimetallic NPs in ILs using Au-Pd NPs as an example. The last part discusses the establishment of multifunctional systems comprising acidic functionalized ILs and metal NPs for a tandem reaction that converts phenolic compounds into alkanes. 


\section{Manipulating the Cation and the Anion}

One of the most intriguing properties of ILs is that the structures of both cation and anion can be modified for a desired application. It is a huge advantage for NP catalysis in ILs compared to those conducted in molecular solvents, since the solvent property of the ILs can be, at least in principle, rationally controlled. It has been well appreciated that both the cation and the anion play important roles in NP catalysis [29,30]. On many occasions, the cation and anion interact simultaneously with the NPs, and consequently, the catalytic property of the NPs originates from the influence of both. Anion effects prove to be more significant, as the anion has a stronger interaction with the surface of NPs. The stabilization of NPs results from the positive charge on the metal surface and is counterbalanced by the absorption of anions [31]. The presence of some special coordination groups in IL can further contribute to the immobilization of NPs [32]. For the sake of clarity, we discuss the effect from the cation and the anion separately. The structures and abbreviations of ILs described in this article are compiled in Figure 1.

Figure 1. The structures and abbreviations of ionic liquids (ILs) described in this article.

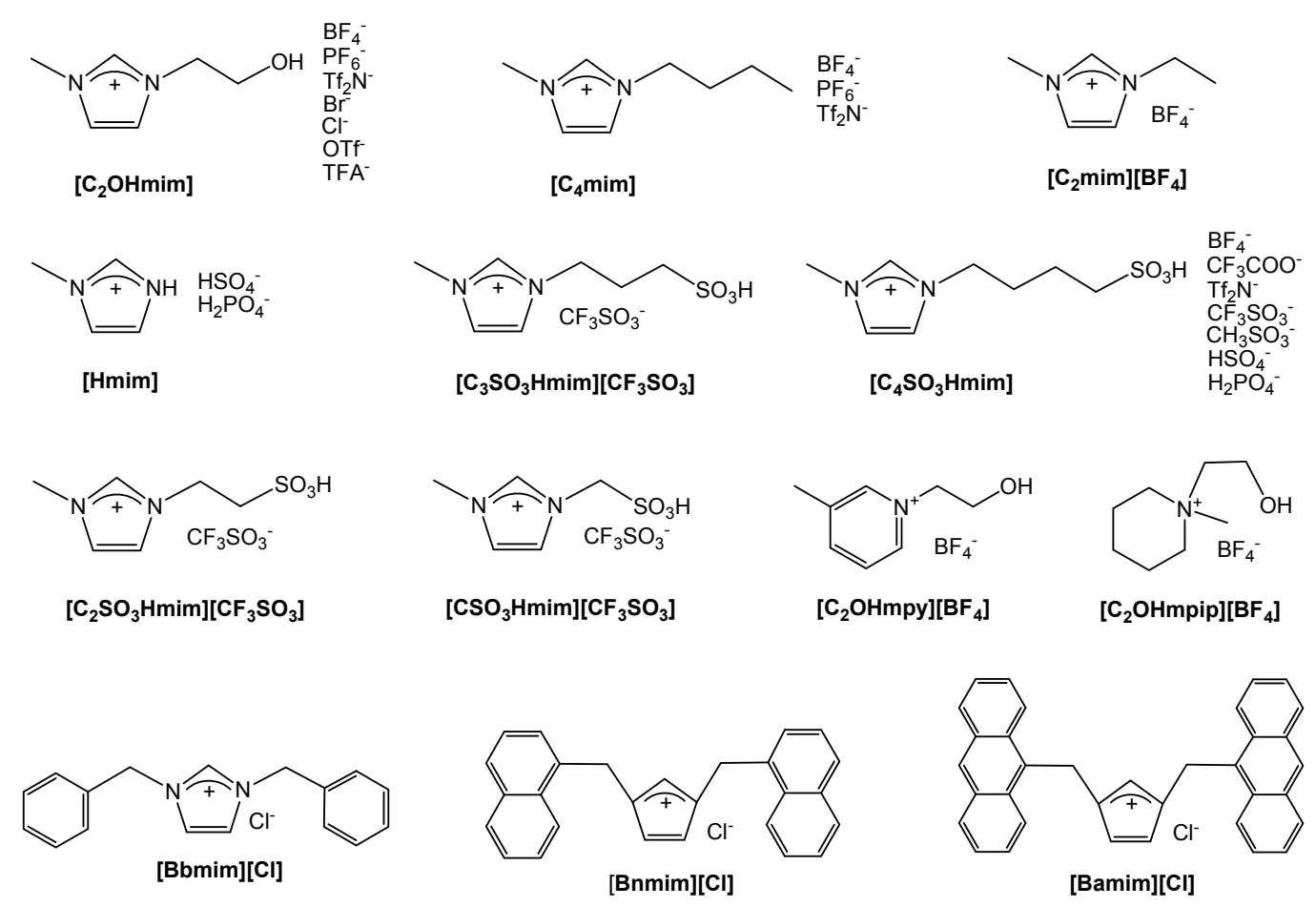

Imidazolium ILs bearing a functional moiety, such as -OR [33,34], $-\mathrm{COOH}[35],-\mathrm{CN}$ [32,36,37] and -SR [38], on the alkyl side chain of the cation were extensively employed as synthesis and reaction media for NPs. Various promotional effects of these functionalized ILs on NP catalysis were reported [27,28]. Herein, we focus on NP catalysis in hydroxyl group functionalized ILs, where the benefits of manipulating the cation structure were adequately demonstrated.

Metal NPs stabilized by certain stabilizers, such as PVP, usually disperse poorly in common ILs, but hydroxyl group functionalized ILs overcome this limitation. PVP is highly soluble in alcohols and water, and by employing the like-dissolves-like principle, it could be anticipated that ILs functionalized with a hydroxyl substituent would be a good solvent to disperse metal NPs stabilized by 
PVP. Indeed, by contrast to PVP-stabilized Rh NPs in 1-ethyl-3-methylimidazolium boron tetrafluoride $\left(\left[\mathrm{C}_{2} \mathrm{mim}\right]\left[\mathrm{BF}_{4}\right]\right)$, where they were insoluble, the same Rh NPs were homogeneously dispersed in the 1-(2-hydroxyethyl)-3-methylimidazoliumboron tetrafluoride $\left(\left[\mathrm{C}_{2} \mathrm{OHmim}\right]\left[\mathrm{BF}_{4}\right]\right)[39]$. Another hydroxyl group functionalized ILs, including those based on pyridinium (such as $\left[\mathrm{C}_{2} \mathrm{OHmpy}\right]\left[\mathrm{BF}_{4}\right]$ ) and pyrrolidinium (such as $\left[\mathrm{C}_{2} \mathrm{OHmpip}\right]\left[\mathrm{BF}_{4}\right]$ ) cations, were also effective in dispersing Rh NPs. Due to the superior dispersion of the Rh NPs in hydroxyl group functionalized ILs, significantly higher catalytic activity was observed. In addition, combined stabilization by PVP and ILs provides Rh NPs with excellent stability, enabling facial recycling and reuse.

Hydroxyl group functionalized ILs are able to promote NP catalysis in many other ways. A good example is their multiple roles beyond a solvent in Pd-catalyzed Suzuki reactions [40]. Compared to non-functionalized ILs, the OH-IL system leads to much better performance. The catalytic system is more active, does not require additional water (which is the case in many previous reports [13,14,41-43]) and, furthermore, is capable of converting challenging substrates, such as hindered and chloro-substituted compounds. The cation plays a critical role in catalyst/substrate activation by directly facilitating a ligand-free catalytic system. First, it promotes the generation of active catalyst. $\mathrm{PdCl}_{2}$, which was used as a pre-catalyst, has to be converted in situ into $\mathrm{Pd}(0)$ species and, consequently, Pd NPs. These Pd NPs act as reservoirs for true catalytic species, which are believed to be a homogeneous Pd complex. Clearly, the generation of $\operatorname{Pd}(0)$ species requires the dissociation of $\mathrm{Cl}^{-}$. Dyson et al. reported that the interaction between $\mathrm{Cl}^{-}$and 1-butyl-3-methylimidazolium $\left(\left[\mathrm{C}_{4} \mathrm{mim}\right]\right)$ cation is $15.4 \mathrm{~kJ} / \mathrm{mol}[44]$ - so weak that the dissociation of a $\mathrm{Cl}^{-}$from $\mathrm{PdCl}_{2}$ likely becomes thermodynamically unfavorable in non-functionalized ILs. On the other hand, hydroxyl group functionalized ILs interact with $\mathrm{Cl}^{-}$much stronger, such that the generation of $\operatorname{Pd}(0)$ is facilitated. In a control experiment in which $\operatorname{Pd}(\mathrm{OAc})_{2}$ are decomposed into Pd NPs in $\left[\mathrm{C}_{4} \mathrm{mim}\right]\left[\mathrm{Tf}_{2} \mathrm{~N}\right]$ and $\left[\mathrm{C}_{2} \mathrm{OHmim}\right]\left[\mathrm{Tf}_{2} \mathrm{~N}\right]$, XPS analysis indicated that the hydroxyl group accelerates the formation of the NPs and helps to protect the NPs from oxidation once formed [45]. The hydroxyl functionality attached to the IL cation is believed to help stabilize the Pd NPs by interacting with the NP surface and the monometallic $\mathrm{Pd}(0)$ species by direct (albeit, weak) coordination, in a similar manner as the nitrile functionalized ILs [36]. In addition, hydroxyl group functionalized ILs prevent the deactivation of catalysts by halides, which are either present as impurities in ILs or accumulated during the reaction. A plausible reaction mechanism and the multiple roles that the functionalized cation plays in the entire catalytic cycle are illustrated in Figure 2.

In some cases, the cations are very bulky, such that the melting point of the IL is too high to be used as a solvent. To evaluate the effect of these cations on NP catalysis, they can be used as additives. The influence of imidazolium-based cation containing bulky peripheral groups on Pd catalyzed Suzuki reaction was investigated with this approach. The imidazolium-based salts, 1,3-bis(9-anthracenylmethyl) imidazolium chloride ([Bamim][Cl]), 1,3-bis(1-naphthalenylmethyl)imidazolium chloride ([Bnmim][Cl]) and 1,3-bis(benzyl methyl)imidazolium chloride $([\mathrm{Bbmim}][\mathrm{Cl}])$, were prepared (see Figure 1 for structures). These salts were subsequently converted to tetrachloropalladate salts by reacting with $\mathrm{PdCl}_{2}$ in acetonitrile. Following that, they were evaluated as pre-catalysts in Suzuki coupling reactions in $\left[\mathrm{C}_{2} \mathrm{mim}\right]\left[\mathrm{Tf}_{2} \mathrm{~N}\right]$. [Bamim $][\mathrm{Cl}]$, which has the largest polycyclic system, provided the highest activities, whereas $[\mathrm{Bbmim}][\mathrm{Cl}]$ provided the lowest. TEM analysis revealed that $5 \mathrm{~nm}$ Pd NPs were generated in situ. These NPs plausibly act as reservoirs for genuine catalytic species. Based on the observation of the existence of NPs in the reaction medium, it is assumed that the anthracene- 
substituents in [Bamim] [Cl] interact most effectively with the NPs, which leads to the higher catalytic activity. Analysis of the packing of $\mathrm{PdCl}_{2}{ }^{-}$[Bamim $][\mathrm{Cl}]$ salt reveals the presence of cavities $\left(\mathrm{ca} .1 \mathrm{~nm}^{3}\right)$ encapsulating organic solvents formed from the faces of the anthracenyl substituents. On the other hand, these cavities do not exist in the other two salts. Probably, these supramolecular forces are retained in the ionic liquid and contribute to the stabilization of NPs [46].

Figure 2. The proposed catalytic cycle for Suzuki coupling and the roles of a hydroxyl group functionalized IL in the catalytic system. Reprinted from Ref. [26], with permission from Elsevier.

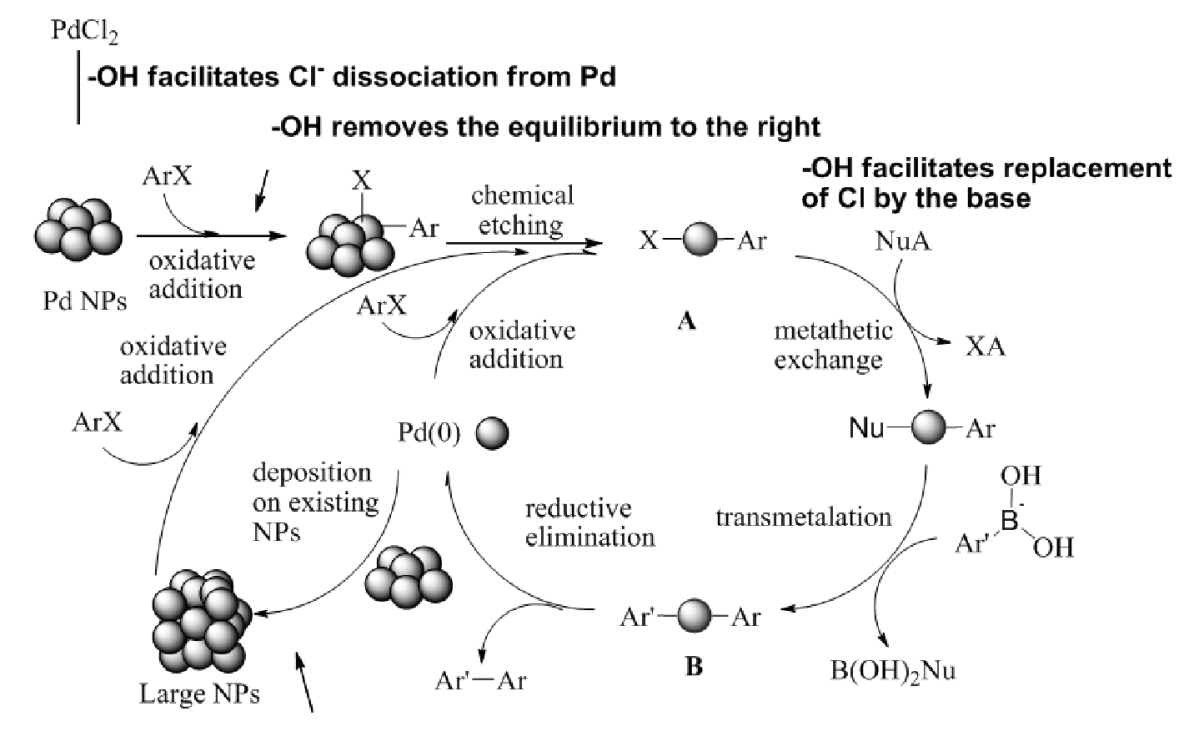

$-\mathrm{OH}$ prevents Pd NPs aggregation $\quad-\mathrm{OH}$ prevents poison of $\mathrm{Pd}$ species by halides

Anion also has a strong influence on the size, shape, aggregation and catalytic properties of NPs $[47,48]$. In the $\mathrm{Rh}$ NP-catalyzed hydrogenation reaction, $\left[\mathrm{BF}_{4}\right]^{-}$and $\left[\mathrm{PF}_{6}\right]^{-}$gave higher conversions compared with $\left[\mathrm{Tf}_{2} \mathrm{~N}\right]^{-}[39]$. Noteworthy, $\left[\mathrm{BF}_{4}\right]^{-}$and $\left[\mathrm{PF}_{6}\right]^{-}$are generally classified as non- (or weakly) coordinating anions, whereas $\left[\mathrm{Tf}_{2} \mathrm{~N}\right]^{-}$may be classified as having intermediate coordinating properties [49]. Therefore, such a phenomenon may be ascribed for that anion that interacts more strongly with the NP surface, diminishing absorption and activation of the substrates. On the other hand, $\left[\mathrm{Tf}_{2} \mathrm{~N}\right]^{-}$provides higher yields compared to other anions in Pd-catalyzed Suzuki reaction [40], presumably the intermediate coordinating property of $\left[\mathrm{Tf}_{2} \mathrm{~N}\right]^{-}$curtails the stabilization of the $\operatorname{Pd}(0)$ species, which is the genuine catalytic species.

In fact, anion and cation do not only influence the catalytic performance of the NPs, but also influence their formation and stabilization. Through DFT computations, a comparison study on the interaction between a $\mathrm{Pd}_{n}$ cluster $(n=1-6,13,14)$ and cation $\left(\left[\mathrm{C}_{1} \mathrm{mim}\right]^{+}\right.$and $\left.\left[\mathrm{C}_{2} \mathrm{mim}\right]^{+}\right)$, as well as between the cluster and anion $\left(\left[\mathrm{BF}_{4}\right]\right.$ ) was conducted (see Figure 3) [31]. It is found that the cation interacts stronger with a $\mathrm{Pd}$ atom, but for all the $\operatorname{Pd}_{n}(n=2-6,13,14)$ clusters, anion interaction is more pronounced. Therefore, cation mainly influences the first step of Pd-NP formation, i.e., the growth of a Pd atom into a Pd dimer, while anion plays a major role in stabilization of a larger Pd cluster. Nevertheless, binding energies (BEs) and the binding Gibbs-free energies (BGFEs) for the IL components do not exceed the corresponding addition energies of an isolated $\mathrm{Pd}$ atom to a $\mathrm{Pd}_{\mathrm{n}}$ cluster. 
In another words, $\mathrm{Pd}-\mathrm{Pd}$ interaction is stronger than the interactions of $\mathrm{Pd}_{\mathrm{x}}$ with both $\left[\mathrm{C}_{1} \mathrm{mim}\right]^{+}$and $\left[\mathrm{BF}_{4}\right]^{-}$. From this, it is clear that NPs in non-functionalized ILs are kinetically stabilized rather than thermodynamically stabilized.

Figure 3. Dependence on $n$ of (a) addition energy of a single $\mathrm{Pd}$ atom to the $\mathrm{Pd}_{n}$ cluster; (b) binding energy of $\left[\mathrm{BF}_{4}\right]^{-}$to $\mathrm{Pd}_{n}$; (c) Binding energy of $\left[\mathrm{C}_{1} \mathrm{mim}\right]^{+}$to $\mathrm{Pd}_{n}$. (A) Electron energy; (B) Gibbs-free energy. Reprinted from Ref. [31], with permission from Wiley.
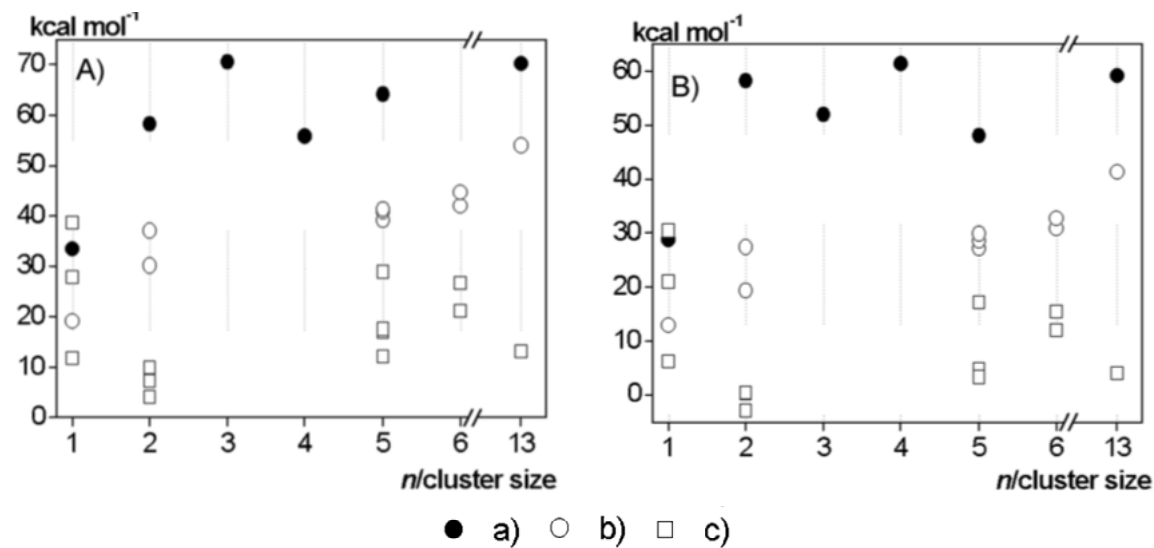

Although ILs do not appear to be sufficient to stabilize NPs, they can act as a type of template that influences the size and topology of NPs during synthesis and, subsequently, act as a stabilizer preventing aggregation and oxidation. A series of NPs were prepared through thermal decomposition of $\mathrm{Pd}(\mathrm{OAc})_{2}[45]$. A considerable anion effect on Pd NP formation rate was observed, with the order: $\left[\mathrm{Tf}_{2} \mathrm{~N}\right]^{-},\left[\mathrm{PF}_{6}\right]^{-}>\left[\mathrm{BF}_{4}\right]^{-}>[\mathrm{OTf}]^{-}>[\mathrm{TFA}]^{-}$. It appears that this trend is related to the nucleophilicity of the anion. The most nucleophilic anions may interact more strongly with the metal precursor and reduce the nucleation process. Indeed, from the series of anions studied, $\left[\mathrm{Tf}_{2} \mathrm{~N}\right]^{-}$and $\left[\mathrm{PF}_{6}\right]^{-}$are the least nucleophilic. Interestingly, the resistance of Pd NPs against oxidation follows the order of $\left[\mathrm{Tf}_{2} \mathrm{~N}\right]>\left[\mathrm{PF}_{6}\right]^{-}>[\mathrm{TFA}]^{-}>[\mathrm{OTf}]^{-}>\left[\mathrm{BF}_{4}\right]^{-}$, which is different from the order of the Pd NP formation rate described above. $\left[\mathrm{Tf}_{2} \mathrm{~N}\right]^{-}$and $\left[\mathrm{PF}_{6}\right]^{-}$are the most hydrophobic anions of the series, and $\left[\mathrm{BF}_{4}\right]^{-}$is the least. It is likely that the increased resistance of the Pd NPs towards oxidation originates from the repelling of water and oxygen by the $\left[\mathrm{PF}_{6}\right]^{-}$and $\left[\mathrm{Tf}_{2} \mathrm{~N}\right]^{-}$anions.

\section{Employment of Additional Stabilizer}

As detailed above, the imidazolium-based ILs can stabilize transition-metal NPs [28]. However, agglomeration may still happen if ILs alone are used as stabilizers, resulting in a decrease of activity during recycling, especially under harsh reaction conditions. The inability of ILs to provide stable NP suspensions for catalysis has led researchers to use additional stabilizers to increase the long-term stability of NPs. When increasing the stability of NPs in ILs, a balance must be considered between stability and reaction reactivity, because over protection of the catalytic active NP surface may result in loss of activity [50]. In this context, different types of stabilizers have been tested, ranging from polymeric materials to ligands, the latter of which have been extensively studied in coordination chemistry. 
Over the years, we have designed, synthesized and evaluated various polymers, as well as ligand-based stabilizers to enhance the performance of NP catalysis in ILs. For polymer type stabilizers, we focused on modified PVP with enhanced performance that is suitable to be used in ILs. For ligand-type stabilizers, bipyridine derivatives are extensively studied. Figure 4 is a collection of the structures and abbreviations for the stabilizers that have been described in this article.

Figure 4. The structures and abbreviations of additional stabilizers described in this article.

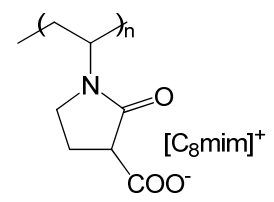

PVP-COO[C 8 mim]<smiles>CC(C)C1CCCC1=O</smiles>

PVP

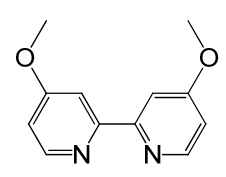

MeO-bipy

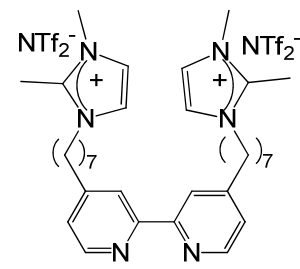

[BIMB|[NTf,]

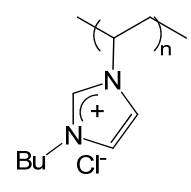

poly[VBIM]CI

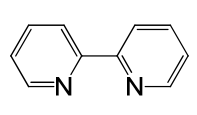

bipy
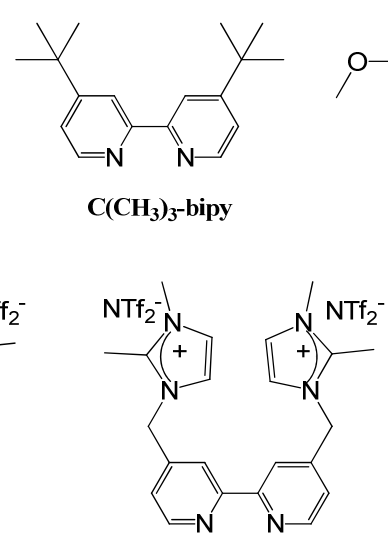

[BIHB]|NTf,]

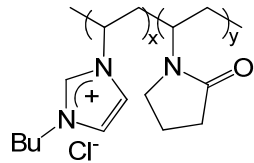

poly[NVP-co-VBIM]CI

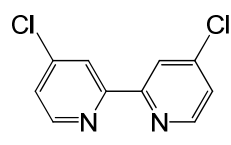

Cl-bipy

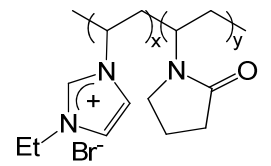

poly[NVP-co-VEIM]Br
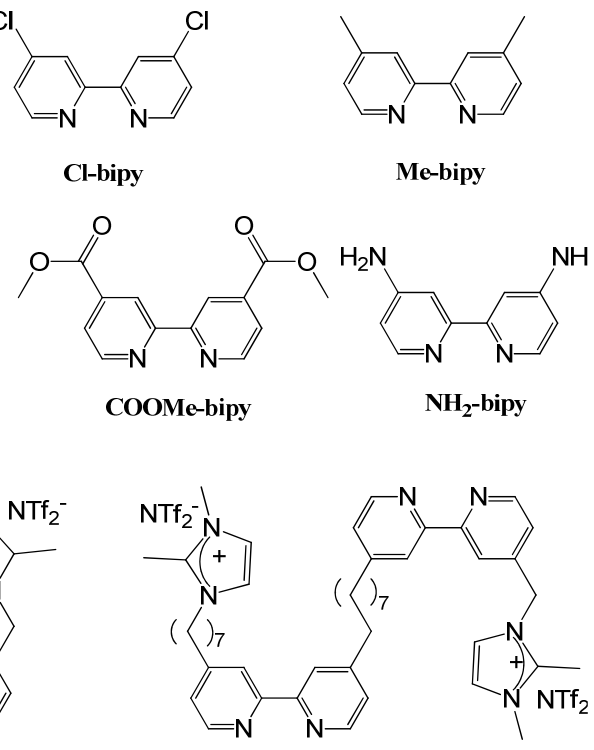

[dibipy][NTf $\mathbf{N}_{2}$

PVP is a common stabilizer for NPs, but it has poor solubility in frequently used ILs, leading to unsatisfactory catalytic activity and stability. Ionic-liquid-like copolymers, poly[( $N$-vinyl-2-pyrrolidone)co-(1-vinyl-3-butylimidazolium chloride)] (poly[NVP-co-VBIM]Cl) and poly[( $N$-vinyl-2-pyrrolidone) -co-(1-vinyl-3-ethylimidazolium bromide)] (poly[NVP-co-VEIM]Br), were reported as NP stabilizers in ILs (see Figure 4 for structures) [51]. The introduction of charged imidazolium moiety into the polymer chain makes the co-polymer compatible with ILs. Rh NPs protected by these two copolymers are more active and stable in benzene hydrogenation compared to the ones protected by PVP or poly[VBIM]Cl. The same polymers also proved to be effective in stabilizing Pt NPs [52] and Ru NPs [53] for selective $\mathrm{C}=\mathrm{O}$ and $\mathrm{NO}_{2}$ reductions [54].

Instead of synthesizing ionic-liquid-like copolymers, our approach is the direct modification of PVP [55-58]. A carboxylic group functionalized PVP with 1-octyl-3-methylimidazolium $\left(\left[\mathrm{C}_{8} \mathrm{mim}\right]\right)$ as the counter cation, termed as PVPCOO[ $\left.\mathrm{C}_{8} \mathrm{mim}\right]$, was synthesized via a five-step protocol (see Scheme 1) [59]. PVPCOO $\left[\mathrm{C}_{8} \mathrm{mim}\right]$ is charged and can be used as stabilizer in ILs. More importantly, metal NPs stabilized by PVPCOO $\left[\mathrm{C}_{8} \mathrm{mim}\right]$ exhibited enhanced stability without compromising catalytic activity compared to PVP stabilized NPs. Unmodified PVP provides the NPs with steric stabilization, as well 
as weak coordination stabilization [60]. $\mathrm{PVPCOO}\left[\mathrm{C}_{8} \mathrm{mim}\right]$ with a carboxylate group attached to the pyrrolidone ring further increases NP stability, by coordination of the carboxylate group with the metal surface and, additionally, via electrostatic stabilization with the formation of a protective electrical double layer. Excellent electrostatic stabilization was confirmed by zeta potential measurements, and the coordination interaction between the carboxylate and NP surface was revealed by IR spectra. As expected, NPs protected by PVPCOO $\left[\mathrm{C}_{8} \mathrm{mim}\right]$ exhibited significantly higher thermal and catalytic stability compared to NPs prepared with PVP, despite their similar initial catalytic activity. Interestingly, in a follow-up study, it was found that the NPs stabilized by carboxylic group modified PVP is pH sensitive, i.e., the NPs are soluble under neutral or basic conditions, but undergo reversible agglomeration under acidic conditions, enabling pH-controlled catalyst recycling [61].

Scheme 1. Synthetic procedure for PVPCOO $\left[\mathrm{C}_{8} \mathrm{mim}\right]$.

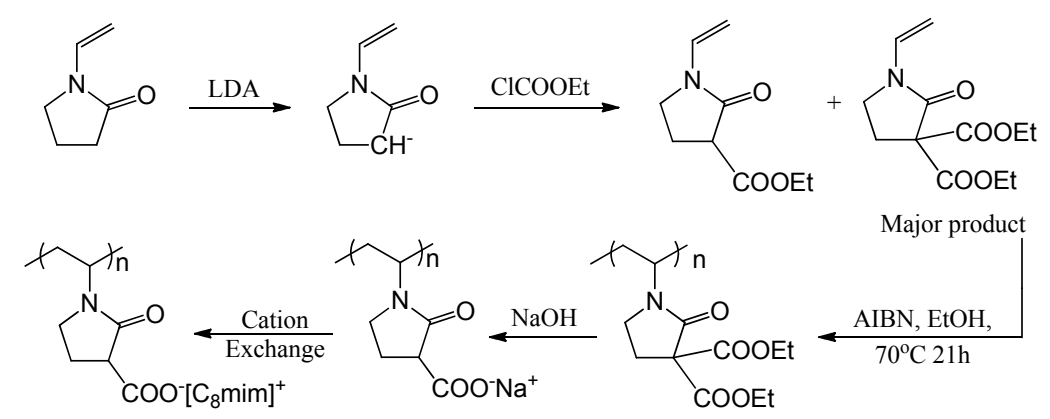

In addition to macromolecular stabilizers, ligands have also been used to stabilize NPs in ILs [62-65]. Since these types of ligands are frequently encountered in homogeneous catalysis, especially those based on phosphine and nitrogen, their electronic and steric effects have been defined and related to catalytic activity. These data should be useful for the description of related effects in nanocatalysis. The influence of five phosphine ligands on the catalytic activity of Rh NPs were analyzed, and the results suggest that the electronic effect, steric effect (bulkiness of the ligand) and the hydrophobicity of ligands are all playing a role [66]. More recently, a work focused on the electronic effect of ligands on the catalytic activity and stability of NPs was performed [67]. A series of Rh NPs was prepared with different 4,4'-modified bipy ligand stabilizers (with $\mathrm{COOMe}, \mathrm{Cl}, \mathrm{Me}$, tert-butyl, $\mathrm{MeO}$ or $\mathrm{NH}_{2}$ substituents at the 4,4'-position; see Figure 4 for structures). The sizes of the $\mathrm{Rh}$ NPs were similar, but their activity in toluene hydrogenation was dramatically different. For the NPs coated with bipy and bipy ligands bearing electron-donating groups, the drop in catalytic activity was pronounced. On the other hand, NPs stabilized by bipy ligands bearing electron-withdrawing groups, such as Cl-bipy and COOMe-bipy, were much more active, but much less stable. From a mechanistic point of view, electron donating ligands interact stronger with NPs compared to electron withdrawing ligands and, therefore, provide better protection. However, the strong interaction also limits the accessibility of the substrate to NPs leading to decreased catalytic activity. To overcome this dilemma, a dimerized-bipy ligand ([dibipy] $\left[\mathrm{NTf}_{2}\right]_{2}$, see Figure 4 for structure) with electron-withdrawing substituents was designed in an attempt to achieve high activity without compromising stability. It is speculated that each bipy unit may dissociate readily, due to the electron withdrawing group attached to the bipyridine. However, the dimeric structure is less likely to undergo complete dissociation from the NP surface (see Figure 5). Therefore, the combined effects enable both higher activities and 
stabilities to be achieved. Indeed, [dibipy] $\left[\mathrm{NTf}_{2}\right]_{2}$ stabilized Rh NPs are much more resistant towards aggregation than those that are stabilized with bipy. The Rh-Rh coordination number of Rh NPs after catalysis obtained by X-ray absorption fine structure (XAFS) analysis, which reflects the size of NPs, is larger for bipy-Rh NPs than [dibipy] $\left[\mathrm{NTf}_{2}\right]_{2}-\mathrm{Rh} \mathrm{NPs}$, suggesting that the smaller size of the [dibipy] $\left[\mathrm{NTf}_{2}\right]_{2}$-stabilized $\mathrm{Rh} \mathrm{NPs}$ is retained.

Figure 5. Representation of the proposed role of bipy (top) and the $\left[\right.$ dibipy] $\left[\mathrm{NTf}_{2}\right]_{2}$ (bottom) during the NP-catalyzed hydrogenation of benzene, which accounts for the higher stability of the dimeric stabilizer. Reprinted from Ref. [67], with permission from Wiley.

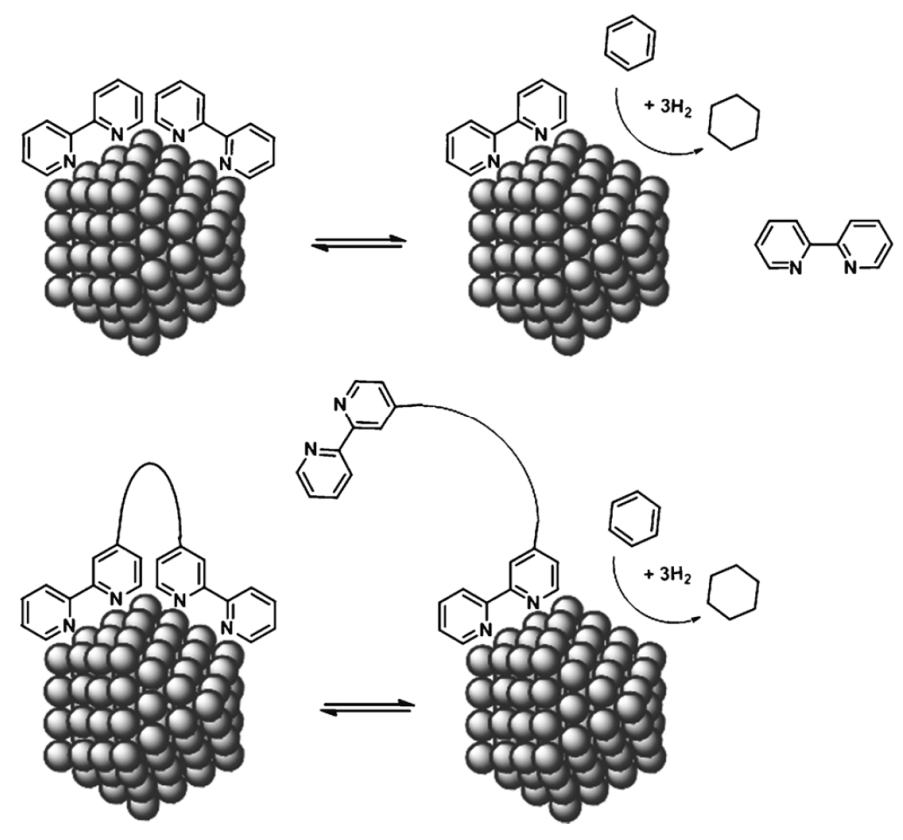

\section{Development of Bimetallic NPs}

Although most research concerning NP catalysis in ILs are based on monometallic NPs, bimetallic NPs are attracting more and more attention, because of their unique structures and physiochemical properties that sometimes exhibit enhanced catalytic performance [68]. Bimetallic NP catalysis in molecular solvents has been a research focus in recent years. However, only a handful of publications of bimetallic NP in ILs are available. These include examples of $\mathrm{Au}-\mathrm{Ag}$ [69,70], $\mathrm{Au}-\mathrm{Pd}$ [71], $\mathrm{Au}-\mathrm{Pt}$ [72], $\mathrm{Cu}-\mathrm{Ru}$ [73] and $\mathrm{Fe}-\mathrm{Ru}$ [74] NPs, some of which were used as catalysts [75-77]. Furthermore, the exact structure of the NPs, the electronic and geometric interplay of the two metals and the subsequent influence on catalysis largely remain elusive. As such, we carried out a detailed case study on $\mathrm{Au}-\mathrm{Pd}$ NPs in ILs [78]. It is noteworthy that Au-Pd NPs are intriguing, because some exhibit improved catalytic activities and increased resistance to poisoning in certain reactions in molecular solvents [79].

In an effort to prepare Pd NPs through thermal decomposition from its acetate [45], an approach for NP synthesis in ILs pioneered by Dupont and Prechtl et al. [24,37], we were aware that introducing a hydroxyl group into the cation can accelerate the formation of NPs and help protect the NPs from further oxidation. Therefore, we extended the method to the synthesis of bimetallic Au-Pd NPs [78]. The synthetic procedure was straight forward. A hydroxyl-functionalized IL, $\left[\mathrm{C}_{2} \mathrm{OHmim}\right]\left[\mathrm{Tf}_{2} \mathrm{~N}\right]$, was 
chosen as solvent in which both $\mathrm{Pd}(\mathrm{OAc})_{2}$ and $\mathrm{Au}(\mathrm{OAc})_{3}$ were dispersed. The decomposition was then conducted at $393 \mathrm{~K}$ under vacuum to remove the volatiles generated. TEM results show that all NPs are spherical and of similar size, at around $4 \mathrm{~nm}$, regardless of the elemental ratios. HRTEM images of pure $\mathrm{Au}$ NPs indicate a crystalline material with a face-centered cubic structure, while similarly exposed planes are present in the HRTEM images of pure Pd and bimetallic Au-Pd NPs. However, TEM and HRTEM are unable to provide further information concerning composition and structure, since $\mathrm{Au}$ and $\mathrm{Pd}$ share the same crystal structure and similar lattice parameters. A variety of other techniques are employed to reveal the exact structure of the Au-Pd NPs.

$\mathrm{Au}-\mathrm{Pd}$ NPs prepared in molecular solvents can adapt both alloy [80] and core-shell structures (see Scheme 2). By combined techniques, we are able to determine the structure of the Au-Pd NPs synthesized in $\left[\mathrm{C}_{2} \mathrm{OHmim}\right]\left[\mathrm{NTf}_{2}\right]$ to be an incomplete core-shell structure-with Au atoms staying in the core, and Pd atoms enriched in the shell (see Scheme 2, right). The key evidences leading to this conclusion include: (1) STEM-EDX (both selected area scan and selected line scan modes) demonstrates that the NPs are bimetallic in nature, instead of mixed Au NPs and Pd NPs; (2) in the XRD pattern, only the diffraction peaks for pure $\mathrm{Au}$ are observed, suggesting the NPs have a crystalline Au core; (3) XPS analysis indicates a surface enrichment of Pd; (4) XAFS curve fitting satisfies the core-shell model better than the alloy model.

Scheme 2. The possible structures of the Au-Pd NPs. (Left) alloy structure; (Middle) core-shell structure ( $\mathrm{Au}$ atoms as the core; however, $\mathrm{Pd}$ atoms could, in principle, also occupy the core); and (Right) partial core-shell structure (Pd-enriched surface layers). Reprinted from Ref. [78], with permission from Wiley.
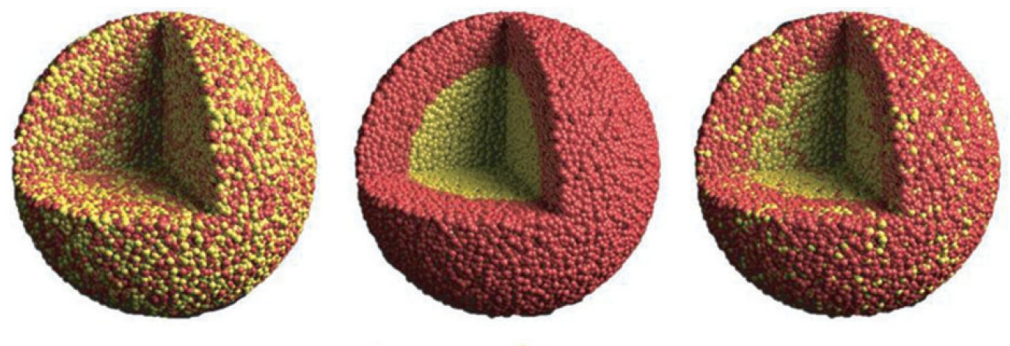

- Pdatoms Au atoms

$\mathrm{Au}$ has relatively higher electron negativity than $\mathrm{Pd}$. It could be anticipated that $\mathrm{Pd}$ will donate electrons to Au when the two are mixed, which is nicely corroborated by the XPS analysis. The Au $3 f 7 / 2$ peak moves to lower BEs when Pd is incorporated into the NP, and the shift increases with increased Pd percentage. The BEs for Pd, on the other hand, exhibit exactly the opposite trend. The Pd $3 \mathrm{~d} 5 / 2$ peak for the pure Pd NPs has a value of $335.5 \mathrm{eV}$, slightly higher than that of Pd metal $(335.1 \mathrm{eV})$. With Au incorporation, the value increases until it reaches a maximum of $335.8 \mathrm{eV}$ with the highest Au content (80\%).

We believe the surface enrichment of Pd and the electronic interplay between Au and Pd in the NPs would influence the catalytic properties. To demonstrate this, the Au-Pd NPs were used to catalyze the dehalogenation of 2-chloronitrobenzene, 4-bromotoluene and 3,5-dibromotoluene (see Scheme 3). This type of reaction is important, as they are relevant to the removal of toxic organic halides in environmental remediation. Not unexpected, in all cases, the bimetallic Au-Pd NPs were superior to 
the Pd NPs, whereas the $\mathrm{Au}$ NPs were completely inactive. The $\mathrm{Au}_{0.8} \mathrm{Pd}_{0.2} \mathrm{NPs}$ are about ten-times more active than the Pd NPs. We attribute the enhanced catalytic activity to two major factors. One is that the Pd atoms, which are responsible for catalysis, are enriched in the NP surface. In addition, the $\mathrm{Pd}$ atoms are electron positive, due to electron donation to Au atoms within the NPs, and this should facilitate reductive elimination of the product that is presumably the rate-determining step.

Scheme 3. Au-Pd NP catalyzed hydrodehalogenation reaction in $\left[\mathrm{C}_{2} \mathrm{OHmim}\right]\left[\mathrm{NTf}_{2}\right]$.

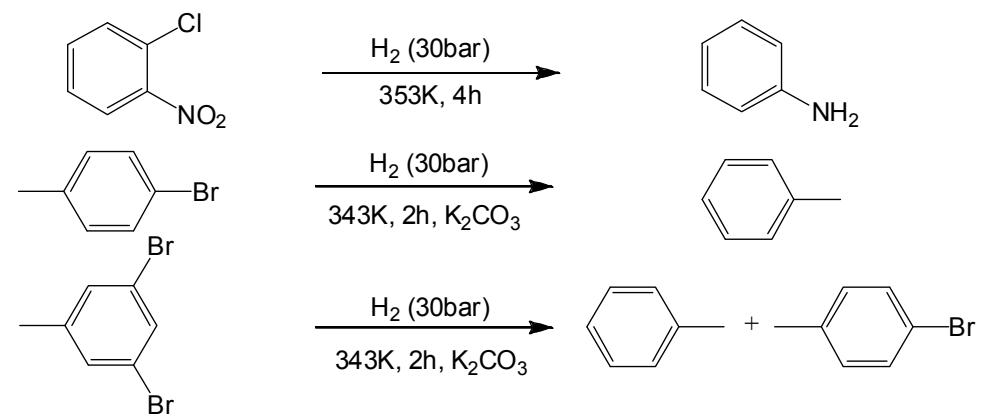

This work demonstrates that IL could be used as an effective media to protect bimetallic NPs. Through the fabrication of NP composition and structure, the electronic and geometric features of NPs can be manipulated, which, in turn, would affect the catalytic property of NPs in ILs.

\section{Designing of Multifunctional System}

It is always desirable that NP catalysts in ILs are highly effective. In this regard, multifunctional systems that integrate a few catalytic steps into a one-pot, catalytic cascade process would prove advantageous, as they could significantly save time and energy, while reducing the waste [26]. Indeed, it represents one of the future trends in green chemistry [81]. Metal NPs and ILs appear to be an ideal couple in constructing multifunctional catalytic systems. Metal NPs will be able to catalyze hydrogenation, oxygenation and coupling reaction, whereas acid or base functionalized ILs could promote dehydration, esterification and alkylation, among many others [82-84].

With this in mind, the possibility of upgrading phenolic compounds derived from lignin into alkane fuels by employing multifunctional NP-IL systems was explored [85]. The essence of transformation from phenol to alkane is the hydrogenation of the aromatic ring and deoxygenation. The conventional hydrodeoxygenation processes is based on NiMo and CoMo sulfite catalysts. To convert a phenolic compound into an alkane, the substrate undergoes hydrogenation and hydrogenolysis, or the other way around (see upper part of Scheme 4 with phenol as an example). Direct deoxygenation of phenol requires high temperature, typically above $400{ }^{\circ} \mathrm{C}$, which makes the traditional catalytic systems problematic, due to high energy consumption, coke accumulation and water-induced catalyst deactivation. Alternatively, phenol can be transformed into cyclohexane by tandem hydrogenation-dehydration reactions under much milder conditions [86-88] (see the lower part of Scheme 4) and would overcome the above mentioned limitations. 
Scheme 4. Two reaction pathways from phenol to cyclohexane: (top) direct hydrodeoxygenation over traditional catalyst; (bottom) tandem hydrogenation-dehydration over multifunctional systems.

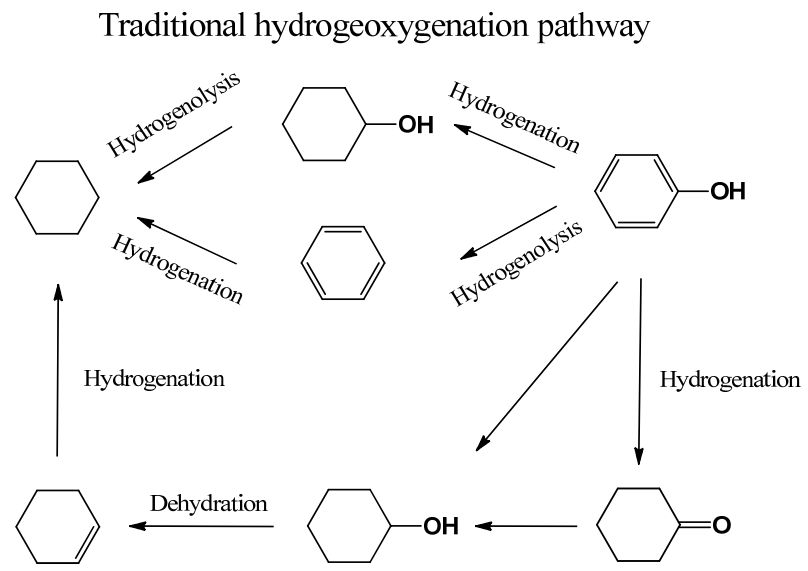

Tandem hydrogenation-dehydration pathway

As hydrogenation reactions can be readily catalyzed by metal NPs in ILs, the major remaining challenge is to develop functionalized ILs that could promote the dehydration reaction under mild conditions. Twelve Brønsted acidic ILs were synthesized, most of which were based on sulfonic acid functionalized ILs. The Hammett acidity functions $\left(H_{0}\right)$ of these ILs were determined spectrophotometrically by evaluating the protonation of an uncharged indicator in acetonitrile [89]. With the same cationic structure, the acidity of the Brønsted acidic ILs differs markedly with different counter anions. Among seven anions being screened, the IL with $\left[\mathrm{CF}_{3} \mathrm{SO}_{3}\right]^{-}$as counter anion exhibits the highest acidity. These ILs were used as additives in promoting the dehydration reaction of cyclohexanol into cyclohexene in $\left[\mathrm{C}_{4} \mathrm{mim}\right]\left[\mathrm{BF}_{4}\right]$, with a good correlation between the strength of the acid and the yield of cyclohexene observed. Following that, metal NP catalysts, including Rh, Pt, Pd and $\mathrm{Ru}$ NPs were combined with the optimized Brønsted acidic IL to convert phenols to their corresponding alkanes in a one-pot process. The $\mathrm{Rh}-\left[\mathrm{C}_{4} \mathrm{SO}_{3} \mathrm{Hmim}\right]\left[\mathrm{CF}_{3} \mathrm{SO}_{3}\right]$ system proved to be most active - high alkane yields were achieved over a wide range of substrates, including methyl phenol, ethyl phenol, anisole and even branched phenols at temperatures as low as $130{ }^{\circ} \mathrm{C}$, with a small metal-to-substrate ratio of 1:300, demonstrating the effectiveness of NP-functionalized IL multifunctional systems (see Figure 6).

Figure 6. Graphic illustration of acid-NP multifunctional system for the upgrading of phenolic compounds into alkanes. Reprinted from Ref. [85], with permission from Wiley.

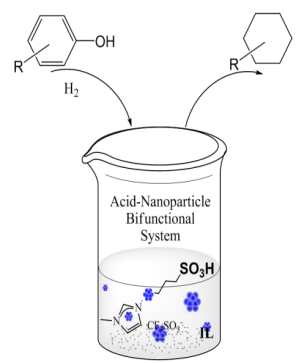




\section{Conclusion and Perspectives}

For metal NPs dispersed in non-functionalized ILs, anion plays a more significant role in stabilizing NPs, as it interacts more strongly with the metal surface than the cation. By changing the anion, the stability and the activity of NPs can be modified to some extent. Nevertheless, these NPs are only kinetically stable and neither anion nor cation could prevent them from agglomeration. The weak interaction between NPs and non-functionalized ILs is the major reason for high catalytic activity, but also induce poor stability/recyclability of NPs. Employing hydroxyl group functionalized ILs can alleviate the problem, as the hydroxyl group provides more stabilization to NPs. Moreover, the hydroxyl group can strongly interact with halide anion, which proved advantageous in generating and stabilizing the catalytically active Pd species in Suzuki reactions.

To further improve the stability of NPs, ILs can be used in conjunction with other stabilizers, such as polymers and ligands. There are three main stabilization mechanisms based on the interaction of the additional stabilizer with the metal surface, namely electrostatic, steric and coordination. We proposed a general strategy for synthesizing stabilizers that provide the NPs with enhanced stability without compromising activity. The strategy is to design a stabilizer that can provide all three stabilization mechanisms. Each of the three stabilizations is manipulated to be not too strong to interfere catalytic activity, but combined, they endow the NPs with excellent stability. The usefulness of the strategy was demonstrated by a carboxylate functionalized PVP polymer. For ligand type stabilizers, a systematic investigation of the ligand electronic effect was conducted. NPs stabilized by less electron donating ligands exhibited higher activity, but lower stability. Based on this, a dimeric ligand with two weakly coordination moieties was designed. This ligand can dissociate from the NP surface easier (to maintain high activity), due to the presence of an electron withdrawing group, but is unlikely to undergo complete dissociation, due to the dimeric nature (so that the stability is maintained).

Bimetallic catalysts have a long history in classical heterogeneous catalysis. Adding a second metal to the first metal can tune catalytic performances, such as activity, selectivity, durability, etc. These benefits seem to be overlooked in the domain of NP catalysis in ILs. With a detailed study on Au-Pd NPs in ILs, it is demonstrated that the addition of $\mathrm{Au}$ into $\mathrm{Pd}$ modifies both the electronic and structural factors of the original Pd NPs, resulting in a significant increase in catalytic activity. So far, such examples are very rare, and we anticipate many more examples to come in the future.

Constructing multifunctional systems that are able to catalyze a few reactions in a row is another promising approach to improve the efficiency of NP catalysis. Careful selection of the catalysts combination and the reaction condition suitable for all the reaction steps to occur are the keys. It is desired that future studies concentrate on the development of catalysts based on inexpensive metals (e.g., $\mathrm{Fe}, \mathrm{Ni}, \mathrm{Co}$ ) for the production of highly value-added chemicals in a one-pot manner.

Compared to homogeneous catalysts, determining the molecular-level mechanistic steps involved in transformations with NP catalysis in ILs is considerably more challenging. Nevertheless, in situ XAFS appears to be a good technique to reveal some aspects of the NPs during reaction. This technique has been applied to follow the formation mechanism of metal NPs in molecular solvents $[90,91]$. We anticipate that the employment in situ XAFS for NP catalysis in the IL phase would bring more fundamental understanding. 
Finally, nanoclusters (NCs) in which the number of metal atoms can be precisely controlled have received considerable research interest. For example, $\mathrm{Au}_{15}, \mathrm{Au}_{18}, \mathrm{Au}_{25}$ [92], $\mathrm{Au}_{38}$ [93] and $\mathrm{Au}_{144} \mathrm{NCs}_{\text {[94] }}$ can all be prepared, and some of them have been fully characterized by single crystal X-ray diffraction [95]. These clusters break down the barriers between molecular systems and NP systems and are potential catalysts with unusual properties. As we are aware, there are no reports concerning the synthesis and catalytic application of NCs in ILs to date. Whether it is possible that ILs can stabilize these NCs, in a similar way as they stabilize NPs, remains a fundamental and intriguing question.

\section{Acknowledgments}

We thank the start-up grant from NUS (R-279-000-368-133) and a AcRF Tier 1 project from MOE (R-279-000-387-112) for financial support.

\section{Conflict of Interest}

The author declares no conflict of interest.

\section{References}

1. Dupont, J.; Fonseca, G.S.; Umpierre, A.P.; Fichtner, P.F.P.; Teixeira, S.R. Transition-Metal Nanoparticles in Imidazolium Ionic Liquids: Recycable Catalysts for Biphasic Hydrogenation Reactions. J. Am. Chem. Soc. 2002, 124, 4228-4229.

2. Lee, J.W.; Shin, J.Y.; Chun, Y.S.; Jang, H.B.; Song, C.E.; Lee, S.-G. Toward Understanding the Origin of Positive Effects of Ionic Liquids on Catalysis: Formation of More Reactive Catalysts and Stabilization of Reactive Intermediates and Transition States in Ionic Liquids. Acc. Chem. Res. 2010, 43, 985-994.

3. Ariga, K.; Vinu, A.; Yamauchi, Y.; Ji, Q.; Hill, J.P. Nanoarchitectonics for Mesoporous Materials. Bull. Chem. Soc. Jpn. 2012, 85, 1-32.

4. Datta, K.K.R.; Reddy, B.V.S.; Ariga, K.; Vinu, A. Gold Nanoparticles Embedded in a Mesoporous Carbon Nitride Stabilizer for Highly Efficient Three-Component Coupling Reaction. Angew. Chem. Int. Ed. 2010, 49, 5961-5965.

5. Yan, N.; Zhao, C.; Luo, C.; Dyson, P.J.; Liu, H.; Kou, Y. One-Step Conversion of Cellobiose to C6-Alcohols Using a Ruthenium Nanocluster Catalyst. J. Am. Chem. Soc. 2006, 128, 8714-8715.

6. Prechtl, M.H.; Scariot, M.; Scholten, J.D.; Machado, G.; Teixeira, S.R.; Dupont, J. Nanoscale $\mathrm{Ru}(0)$ particles: Arene hydrogenation catalysts in imidazolium ionic liquids. Inorg. Chem. 2008, 47, 8995-9001.

7. Stratton, S.A.; Luska, K.L.; Moores, A. Rhodium nanoparticles stabilized with phosphine functionalized imidazolium ionic liquids as recyclable arene hydrogenation catalysts. Catal. Today 2012, 183, 96-100.

8. Roucoux, A.; Nowicki, A.; Philippot, K. Rhodium and Ruthenium Nanoparticles in Catalysis; Wiley-VCH Verlag GmbH \& Co. KGaA: Weinheim, Germany, 2008; pp. 349-388. 
9. Leger, B.; Denicourt-Nowicki, A.; Olivier-Bourbigou, H.; Roucoux, A. Imidazolium-functionalized bipyridine derivatives: a promising family of ligands for catalytical $\mathrm{Rh}(0)$ colloids. Tetrahedron Lett. 2009, 50, 6531-6533.

10. Seddon, K.R.; Stark, A. Selective catalytic oxidation of benzyl alcohol and alkylbenzenes in ionic liquids. Green Chem. 2002, 4, 119-123.

11. Qiu, L.; Liu, B.; Peng, Y.; Yan, F. Fabrication of ionic liquid-functionalized polypyrrole nanotubes decorated with platinum nanoparticles and their electrocatalytic oxidation of methanol. Chem. Commun. 2011, 47, 2934-2936.

12. Balanta, A.; Godard, C.; Claver, C. Pd nanoparticles for C-C coupling reactions. Chem. Soc. Rev. 2011, 40, 4973-4985.

13. Fernandez, F.; Cordero, B.; Durand, J.; Muller, G.; Malbosc, F.; Kihn, Y.; Teuma, E.; Gomez, M. Palladium catalyzed Suzuki C-C couplings in an ionic liquid: Nanoparticles responsible for the catalytic activity. Dalton Trans. 2007, 5572-5581.

14. Durand, J.; Teuma, E.; Malbosc, F.; Kihn, Y.; Gómez, M. Palladium nanoparticles immobilized in ionic liquid: An outstanding catalyst for the Suzuki C-C coupling. Catal. Commun. 2008, 9, 273-275.

15. Calò, V.; Nacci, A.; Monopoli, A.; Cotugno, P. Palladium-Nanoparticle-Catalysed Ullmann Reactions in Ionic Liquids with Aldehydes as the Reductants: Scope and Mechanism. Chem. Eur. J. 2009, 15, 1272-1279.

16. Cheng, J.; Tang, L.; Xu, J. An Economical, Green Pathway to Biaryls: Palladium Nanoparticles Catalyzed Ullmann Reaction in Ionic Liquid/Supercritical Carbon Dioxide System. Adv. Synth. Catal. 2010, 352, 3275-3286.

17. Xiao, C.-X.; Cai, Z.-P.; Wang, T.; Kou, Y.; Yan, N. Aqueous-phase Fischer-Tropsch synthesis with a ruthenium nanocluster catalyst. Angew. Chem. Int. Ed. 2008, 47, 746-749.

18. Yinghuai, Z.; Widjaja, E.; Pei Sia, S.L.; Zhan, W.; Carpenter, K.; Maguire, J.A.; Hosmane, N.S.; Hawthorne, M.F. Ruthenium(0) Nanoparticle-Catalyzed Isotope Exchange between $10 \mathrm{~B}$ and 11 B Nuclei in Decaborane(14). J. Am. Chem. Soc. 2007, 129, 6507-6512.

19. Geldbach, T.J.; Zhao, D.; Castillo, N.C.; Laurenczy, G.; Weyershausen, B.; Dyson, P.J. Biphasic Hydrosilylation in Ionic Liquids: A Process Set for Industrial Implementation. J. Am. Chem. Soc. 2006, 128, 9773-9780.

20. Yinghuai, Z.; Chenyan, K.; Peng, A.T.; Emi, A.; Monalisa, W.; Kui-Jin Louis, L.; Hosmane, N.S.; Maguire, J.A. Catalytic Phenylborylation Reaction by Iridium(0) Nanoparticles Produced from Hydridoiridium Carborane. Inorg. Chem. 2008, 47, 5756-5761.

21. Lin, Q.; Yang, C.; Jiang, W.; Chen, H.; Li, X. Carbonylation of iodobenzene catalyzed by water-souble palladium-phosphine complexes in ionic liquid. J. Mol. Catal. A 2007, 264, 17-21.

22. Fei, Z.; Geldbach, T.J.; Zhao, D.; Dyson, P.J. From dysfunction to bis-function: On the design and applications of functionalized ionic liquids. Chem. Eur. J. 2006, 12, 2122-2130.

23. Dupont, J.; Scholten, J.D. On the structural and surface properties of transition-metal nanoparticles in ionic liquids. Chem. Soc. Rev. 2010, 39, 1780-1804.

24. Prechtl, M.H.G.; Campbell, P.S.; Scholten, J.D.; Fraser, G.B.; Machado, G.; Santini, C.C.; Dupont, J.; Chauvin, Y. Imidazolium ionic liquids as promoters and stabilizing agents for the 
preparation of metal( 0$)$ nanoparticles by reduction and decomposition of organometallic complexes. Nanoscale 2010, 2, 2601-2606.

25. Prechtl, M.H.G.; Scholten, J.D.; Dupont, J. Carbon-Carbon Cross Coupling Reactions in Ionic Liquids Catalysed by Palladium Metal Nanoparticles. Molecules 2010, 15, 3441-3461.

26. Yan, N.; Xiao, C.; Kou, Y. Transition metal nanoparticle catalysis in green solvents. Coord. Chem. Rev. 2010, 254, 1179-1218.

27. Luska, K.L.; Moores, A. Functionalized Ionic Liquids for the Synthesis of Metal Nanoparticles and their Application in Catalysis. ChemCatChem 2012, 4, 1534-1546.

28. Scholten, J.D.; Leal, B.C.; Dupont, J. Transition Metal Nanoparticle Catalysis in Ionic Liquids. ACS Catal. 2012, 2, 184-200.

29. Neouze, M.-A. About the interactions between nanoparticles and imidazolium moieties: emergence of original hybrid materials. J. Mater. Sci. 2010, 20, 9593-9607.

30. Vollmer, C.; Janiak, C. Naked metal nanoparticles from metal carbonyls in ionic liquids: Easy synthesis and stabilization. Coord. Chem. Rev. 2011, 255, 2039-2057.

31. Katsyuba, S.A.; Zvereva, E.E.; Yan, N.; Yuan, X.; Kou, Y.; Dyson, P.J. Rationalization of Solvation and Stabilization of Palladium Nanoparticles in Imidazolium-Based Ionic Liquids by DFT and Vibrational Spectroscopy. ChemPhysChem 2012, 13, 1781-1790.

32. Zhao, D.; Fei, Z.; Geldbach, T.J.; Scopelliti, R.; Dyson, P.J. Nitrile-Functionalized Pyridinium Ionic Liquids: Synthesis, Characterization, and Their Application in Carbon-Carbon Coupling Reactions. J. Am. Chem. Soc. 2004, 126, 15876-15882.

33. Schrekker, H.S.; Gelesky, M.A.; Stracke, M.P.; Schrekker, C.M.L.; Machado, G.; Teixeira, S.R.; Rubim, J.C.; Dupont, J. Disclosure of the imidazolium cation coordination and stabilization mode in ionic liquid stabilized gold(0) nanoparticles. J. Colloid Interface Sci. 2007, 316, 189-195.

34. Yang, X.; Fei, Z.; Geldbach, T.J.; Phillips, A.D.; Hartinger, C.G.; Li, Y.; Dyson, P.J. Suzuki Coupling Reactions in Ether-Functionalized Ionic Liquids: The Importance of Weakly Interacting Cations. Organometallics 2008, 27, 3971-3977.

35. Zhang, H.; Cui, H. Synthesis and Characterization of Functionalized Ionic Liquid-Stabilized Metal (Gold and Platinum) Nanoparticles and Metal Nanoparticle/Carbon Nanotube Hybrids. Langmuir 2009, 25, 2604-2612.

36. Fei, Z.; Zhao, D.; Pieraccini, D.; Ang, W.H.; Geldbach, T.J.; Scopelliti, R.; Chiappe, C.; Dyson, P.J. Development of Nitrile-Functionalized Ionic Liquids for $\mathrm{C}-\mathrm{C}$ Coupling Reactions: Implication of Carbene and Nanoparticle Catalysts. Organometallics 2007, 26, 1588-1598.

37. Venkatesan, R.; Prechtl, M.H.G.; Scholten, J.D.; Pezzi, R.P.; Machado, G.; Dupont, J. Palladium nanoparticle catalysts in ionic liquids: Synthesis, characterisation and selective partial hydrogenation of alkynes to Z-alkenes. J. Mater. Sci. 2011, 21, 3030-3036.

38. Tatumi, R.; Fujihara, H. Remarkably stable gold nanoparticles functionalized with a zwitterionic liquid based on imidazolium sulfonate in a high concentration of aqueous electrolyte and ionic liquid. Chem. Commun. 2005, 83-85.

39. Yang, X.; Yan, N.; Fei, Z.; Crespo-Quesada, R.M.; Laurenczy, G.; Kiwi-Minsker, L.; Kou, Y.; Li, Y.; Dyson, P.J. Biphasic Hydrogenation over PVP Stabilized Rh Nanoparticles in Hydroxyl Functionalized Ionic Liquids. Inorg. Chem. 2008, 47, 7444-7446. 
40. Yan, N.; Yang, X.; Fei, Z.; Li, Y.; Kou, Y.; Dyson, P.J. Solvent-enhanced coupling of sterically hindered reagents and aryl chlorides using functionalized ionic liquids. Organometallics 2009, 28, 937-939.

41. Mathews, C.J.; Smith, P.J.; Welton, T. Palladium catalysed Suzuki cross-coupling reactions in ambient temperature ionic liquids. Chem. Commun. 2000, 1249-1250.

42. Rajagopal, R.; Jarikote, D.V.; Srinivasan, K.V. Ultrasound promoted Suzuki cross-coupling reactions in ionic liquid at ambient conditions. Chem. Commun. 2002, 616-617.

43. Wang, R.; Twamley, B.; Shreeve, J.N.M. A Highly Efficient, Recyclable Catalyst for C-C Coupling Reactions in Ionic Liquids: Pyrazolyl-Functionalized $N$-Heterocyclic Carbene Complex of Palladium(II). J. Org. Chem. 2005, 71, 426-429.

44. Daguenet, C.; Dyson, P.J. Inhibition of Catalytic Activity in Ionic Liquids: Implications for Catalyst Design and the Effect of Cosolvents. Organometallics 2004, 23, 6080-6083.

45. Yuan, X.; Yan, N.; Katsyuba, S.A.; Zvereva, E.E.; Kou, Y.; Dyson, P.J. A remarkable anion effect on palladium nanoparticle formation and stabilization in hydroxyl-functionalized ionic liquids. Phys. Chem. Chem. Phys. 2012, 14, 6026-6033.

46. Song, H.; Yan, N.; Fei, Z.; Kilpin, K.J.; Scopelliti, R.; Li, X.; Dyson, P.J. Evaluation of ionic liquid soluble imidazolium tetrachloropalladate pre-catalysts in Suzuki coupling reactions. Catal. Today 2012, 183, 172-177.

47. Chiappe, C.; Pieraccini, D.; Zhao, D.; Fei, Z.; Dyson, P.J. Remarkable Anion and Cation Effects on Stille Reactions in Functionalised Ionic Liquids. Adv. Synth. Catal. 2006, 348, 68-74.

48. Khare, V.; Li, Z.; Mantion, A.; Ayi, A.A.; Sonkaria, S.; Voelk1, A.; Thunemann, A.F.; Taubert, A. Strong anion effects on gold nanoparticle formation in ionic liquids. J. Mater. Sci. 2010, 20, 1332-1339.

49. Williams, D.B.; Stoll, M.E.; Scott, B.L.; Costa, D.A.; Oldham, J.W.J. Coordination chemistry of the bis(trifluoromethylsulfonyl)imide anion: molecular interactions in room temperature ionic liquids. Chem. Commun. 2005, 1438-1440.

50. Yuan, Y.; Yan, N.; Dyson, P.J. Advances in the Rational Design of Rhodium Nanoparticle Catalysts: Control via Manipulation of the Nanoparticle Core and Stabilizer. ACS Catal. 2012, 2, 1057-1069.

51. Zhao, C.; Wang, H.-Z.; Yan, N.; Xiao, C.-X.; Mu, X.-D.; Dyson, P.J.; Kou, Y. Ionic-liquid-like copolymer stabilized nanocatalysts in ionic liquids: II. Rhodium-catalyzed hydrogenation of arenes. J. Catal. 2007, 250, 33-40.

52. Yuan, X.; Yan, N.; Xiao, C.; Li, C.; Fei, Z.; Cai, Z.; Kou, Y.; Dyson, P.J. Highly selective hydrogenation of aromatic chloronitro compounds to aromatic chloroamines with ionic-liquid-like copolymer stabilized platinum nanocatalysts in ionic liquids. Green Chem. 2010, 12, 228-233.

53. Zou, M.; Mu, X.; Yan, N.; Kou, Y. Selective hydrogenation of cinnamaldehyde by ionic copolymer-stabilized Pt nanoparticles in ionic liquids. Cuihua Xuebao 2007, 28, 389-391.

54. Yuan, Y.; Yao, S.; Wang, M.; Lou, S.; Yan, N. Recent Progress in Chemoselective Hydrogenation of $\alpha, \beta$-Unsaturated Aldehyde to Unsaturated Alcohol Over Nanomaterials. Curr. Org. Chem. 2013, 17, 400-413. 
55. Yan, N.; Zhang, J.-G.; Tong, Y.; Yao, S.; Xiao, C.; Li, Z.; Kou, Y. Solubility adjustable nanoparticles stabilized by a novel PVP based family: Synthesis, characterization and catalytic properties. Chem. Commun. 2009, 4423-4425.

56. Yan, N.; Zhang, J.; Yuan, Y.; Chen, G.-T.; Dyson, P.J.; Li, Z.-C.; Kou, Y. Thermoresponsive polymers based on polyvinylpyrrolidone: Applications in nanoparticle catalysis. Chem. Commun. 2010, 46, 1631-1633.

57. Zhang, J.; Yuan, Y.; Kilpin, K.J.; Kou, Y.; Dyson, P.J.; Yan, N. Thermally responsive gold nanocatalysts based on a modified poly-vinylpyrrolidone. J. Mol. Catal. A 2013, 371, 29-35.

58. Chen, G.-T.; Wang, C.-H.; Zhang, J.-G.; Wang, Y.; Zhang, R.; Du, F.-S.; Yan, N.; Kou, Y.; Li, Z.-C. Toward Functionalization of Thermoresponsive Poly( $N$-vinyl-2-pyrrolidone). Macromolecules 2010, 43, 9972-9981.

59. Yan, N.; Yuan, Y.; Dyson, P.J. Rhodium nanoparticle catalysts stabilized with a polymer that enhances stability without compromising activity. Chem. Commun. 2011, 47, 2529-2531.

60. Roucoux, A.; Schulz, J.; Patin, H. Reduced Transition Metal Colloids: A Novel Family of Reusable Catalysts? Chem. Rev. 2002, 102, 3757-3778.

61. Yuan, Y.; Yan, N.; Dyson, P.J. pH-Sensitive Gold Nanoparticle Catalysts for the Aerobic Oxidation of Alcohols. Inorg. Chem. 2011, 50, 11069-11074.

62. Axet, M.R.; Castillon, S.; Claver, C.; Philippot, K.; Lecante, P.; Chaudret, B. Chiral diphosphite-modified rhodium(0) nanoparticles: Catalyst reservoir for styrene hydroformylation. Eur. J. Inorg. Chem. 2008, 3460-3466.

63. Salas, G.; Santini, C.C.; Philippot, K.; Colliere, V.; Chaudret, B.; Fenet, B.; Fazzini, P.F. Influence of amines on the size control of in situ synthesized ruthenium nanoparticles in imidazolium ionic liquids. Dalton Trans. 2011, 40, 4660-4668.

64. Denicourt-Nowicki, A.; Leger, B.; Roucoux, A. N-Donor ligands based on bipyridine and ionic liquids: an efficient partnership to stabilize rhodium colloids. Focus on oxygen-containing compounds hydrogenation. Phys. Chem. Chem. Phys. 2011, 13, 13510-13517.

65. Dykeman, R.R.; Yan, N.; Scopelliti, R.; Dyson, P.J. Enhanced rate of arene hydrogenation with imidazolium functionalized bipyridine stabilized rhodium nanoparticle catalysts. Inorg. Chem. 2011, 50, 717-719.

66. Snelders, D.J.M.; Yan, N.; Gan, W.; Laurenczy, G.; Dyson, P.J. Tuning the Chemoselectivity of Rh Nanoparticle Catalysts by Site-Selective Poisoning with Phosphine Ligands: The Hydrogenation of Functionalized Aromatic Compounds. ACS Catal. 2012, 2, 201-207.

67. Dykeman, R.R.; Yuan, Y.; Yan, N.; Asakura, H.; Teramura, K.; Tanaka, T.; Dyson, P.J. Rational Design of a Molecular Nanocatalyst-Stabilizer that Enhances both Catalytic Activity and Nanoparticle Stability. ChemCatChem 2012, 4, 1907-1910.

68. Liu, X.; Liu, X. Bimetallic Nanoparticles: Kinetic Control Matters. Angew. Chem. Int. Ed. 2012, $51,3311-3313$.

69. Okazaki, K.-I.; Kiyama, T.; Hirahara, K.; Tanaka, N.; Kuwabata, S.; Torimoto, T. Single-step synthesis of gold-silver alloy nanoparticles in ionic liquids by a sputter deposition technique. Chem. Commun. 2008, 691-693. 
70. Pearson, A.; O'Mullane, A.P.; Bansal, V.; Bhargava, S.K. Galvanic replacement mediated transformation of $\mathrm{Ag}$ nanospheres into dendritic $\mathrm{Au}-\mathrm{Ag}$ nanostructures in the ionic liquid [BMIM][BF4]. Chem. Commun. 2010, 46, 731-733.

71. Dash, P.; Scott, R.W.J. 1-Methylimidazole stabilization of gold nanoparticles in imidazolium ionic liquids. Chem. Commun. 2009, 812-814.

72. Xiao, F.; Zhao, F.; Mei, D.; Mo, Z.; Zeng, B. Nonenzymatic glucose sensor based on ultrasonic-electrodeposition of bimetallic PtM $(\mathrm{M}=\mathrm{Ru}, \mathrm{Pd}$ and $\mathrm{Au})$ nanoparticles on carbon nanotubes-ionic liquid composite film. Biosens. Bioelectron. 2009, 24, 3481-3486.

73. Arquilliere, P.P.; Santini, C.C.; Haumesser, P.H.; Aouine, M. Synthesis of copper and copper-ruthenium nanoparticles in ionic liquids for the metallization of advanced interconnect structures. ECS Trans. 2011, 35, 11-16.

74. Andanson, J.-M.; Marx, S.; Baiker, A. Selective hydrogenation of cyclohexenone on iron-ruthenium nano-particles suspended in ionic liquids and $\mathrm{CO}_{2}$-expanded ionic liquids. Catal. Sci. Technol. 2012, 2, 1403-1409.

75. Dash, P.; Dehm, N.A.; Scott, R.W.J. Bimetallic PdAu nanoparticles as hydrogenation catalysts in imidazolium ionic liquids. J. Mol. Catal. A 2008, 286, 114-119.

76. Dash, P.; Miller, S.M.; Scott, R.W.J. Stabilizing nanoparticle catalysts in imidazolium-based ionic liquids: A comparative study. J. Mol. Catal. A 2010, 329, 86-95.

77. Hu, B.; Wu, T.; Ding, K.; Zhou, X.; Jiang, T.; Han, B. Seeding Growth of Pd/Au Bimetallic Nanoparticles on Highly Cross-Linked Polymer Microspheres with Ionic Liquid and Solvent-Free Hydrogenation. J. Phys. Chem. C 2010, 114, 3396-3400.

78. Yuan, X.; Sun, G.; Asakura, H.; Tanaka, T.; Chen, X.; Yuan, Y.; Laurenczy, G.; Kou, Y.; Dyson, P.J.; Yan, N. Development of Palladium Surface-Enriched Heteronuclear Au-Pd Nanoparticle Dehalogenation Catalysts in an Ionic Liquid. Chem. Eur. J. 2013, 19, 1227-1234.

79. Hutchings, G.J. Nanocrystalline gold and gold-palladium alloy oxidation catalysts: A personal reflection on the nature of the active sites. Dalton Trans. 2008, 5523-5536.

80. Yang, X.; Chen, D.; Liao, S.; Song, H.; Li, Y.; Fu, Z.; Su, Y. High-performance Pd-Au bimetallic catalyst with mesoporous silica nanoparticles as support and its catalysis of cinnamaldehyde hydrogenation. J. Catal. 2012, 291, 36-43.

81. Sheldon, R.A. E factors, green chemistry and catalysis: An odyssey. Chem. Commun. 2008, 3352-3365.

82. Pinto, A.C.; Lapis, A.A.M.; da Silva, B.V.; Bastos, R.S.; Dupont, J.; Neto, B.A.D. Pronounced ionic liquid effect in the synthesis of biologically active isatin-3-oxime derivatives under acid catalysis. Tetrahedron Lett. 2008, 49, 5639-5641.

83. Hajipour, A.R.; Rajaei, A.; Ruoho, A.E. A mild and efficient method for preparation of azides from alcohols using acidic ionic liquid [H-NMP]HSO . Tetrahedron Lett. 2009, 50, 708-711.

84. Harmer, M.A.; Junk, C.P.; Rostovtsev, V.V.; Marshall, W.J.; Grieco, L.M.; Vickery, J.; Miller, R.; Work, S. Catalytic reactions using superacids in new types of ionic liquids. Green Chem. 2009, 11, 517-525.

85. Yan, N.; Yuan, Y.; Dykeman, R.; Kou, Y.; Dyson, P.J. Hydrodeoxygenation of Lignin-Derived Phenols into Alkanes by Using Nanoparticle Catalysts Combined with Bronsted Acidic Ionic Liquids. Angew. Chem. Int. Ed. 2010, 49, 5549-5553. 
86. Yan, N.; Zhao, C.; Dyson, P.J.; Wang, C.; Liu, L.-T.; Kou, Y. Selective degradation of wood lignin over noble-metal catalysts in a two-step process. ChemSusChem 2008, 1, 626-629.

87. Zhao, C.; Kou, Y.; Lemonidou, A.A.; Li, X.; Lercher, J.A. Hydrodeoxygenation of bio-derived phenols to hydrocarbons using RANEY $\mathrm{Ni}$ and $\mathrm{Nafion} / \mathrm{SiO}_{2}$ catalysts. Chem. Commun. 2010, 46, 412-414.

88. Zhao, C.; Kou, Y.; Lemonidou, A.A.; Li, X.; Lercher, J.A. Highly Selective Catalytic Conversion of Phenolic Bio-Oil to Alkanes. Angew. Chem. Int. Ed. 2009, 48, 3987-3990.

89. Thomazeau, C.; Olivier-Bourbigou, H.; Magna, L.; Luts, S.; Gilbert, B. Determination of an Acidic Scale in Room Temperature Ionic Liquids. J. Am. Chem. Soc. 2003, 125, 5264-5265.

90. Asakura, H.; Teramura, K.; Shishido, T.; Tanaka, T.; Yan, N.; Xiao, C.X.; Yao, S.Y.; Kou, Y. In situ time-resolved DXAFS study of Rh nanoparticle formation mechanism in ethylene glycol at elevated temperature. Phys. Chem. Chem. Phys. 2012, 14, 2983-2990.

91. Yao, S.; Yuan, Y.; Xiao, C.; Li, W.; Kou, Y.; Dyson, P.J.; Yan, N.; Asakura, H.; Teramura, K.; Tanaka, T. Insights into the Formation Mechanism of Rhodium Nanocubes. J. Phys. Chem. C 2012, 116, 15076-15086.

92. Yu, Y.; Chen, X.; Yao, Q.; Yu, Y.; Yan, N.; Xie, J. Scalable and Precise Synthesis of Thiolated Au10-12, Au15, Au18, and Au25 Nanoclusters via pH Controlled CO Reduction. Chem. Mater. 2013, 25, 946-952.

93. Toikkanen, O.; Ruiz, V.; Rönnholm, G.; Kalkkinen, N.; Liljeroth, P.; Quinn, B.M. Synthesis and Stability of Monolayer-Protected Au38 Clusters. J. Am. Chem. Soc. 2008, 130, 11049-11055.

94. Qian, H.; Jin, R. Ambient Synthesis of Au144(SR)60 Nanoclusters in Methanol. Chem. Mater. 2011, 23, 2209-2217.

95. Jadzinsky, P.D.; Calero, G.; Ackerson, C.J.; Bushnell, D.A.; Kornberg, R.D. Structure of a Thiol Monolayer-Protected Gold Nanoparticle at 1.1 Å Resolution. Science 2007, 318, 430-433.

(C) 2013 by the authors; licensee MDPI, Basel, Switzerland. This article is an open access article distributed under the terms and conditions of the Creative Commons Attribution license (http://creativecommons.org/licenses/by/3.0/). 